\title{
Gathering Experience with the United Nations Human Settlements Program in Nairobi, Kenya.
}

JENNIFER VENEMA

In the fall quarter of 2007, Jennifer Venema went to Nairobi, Kenia, for a voluntary intership at the headquarters of the United Nations Human Settelements Program. She writes passionately about her fascinating experience in a totally new and sometimes conflictous environment, and sets an example for planning students.

Kenya is a land of complexities and contradictions. When I traveled there, it was the first time in my life when I have lived such complexities. As a city and regional planning major, I went there to intern as a volunteer at the United Nations. I am an idealist, and I wanted to believe that, through my work, I could offer knowledge and skills that would improve someone's life somewhere--or at least that I could learn things through this internship which would allow me to make a contribution in the long term. Yet, my identity there was shaped by my being white: I was one of the elite, equipped with a college education and the ability to afford to come overseas.

I went despite my status as a typical in-debt American college student. I have been told that even the access to loans is a sign of wealth--it is a luxury most people in the world do not have; rather, their only desperate option for money comes through selling their children into prostitution or slavery. Being made so brutally aware of my place in the vast divides of society so suddenly--something I always knew but had never experienced--I have realized that I am not merely a sympathetic person working to do good, but that I am a sympathetic person who must learn how to utilize the gifts I have without incapacitating myself with confusion over my own obligations and entitlements.

Life in Kenya was very unreal and had a novel-like quality to it. It was the first time in my life that I have felt like a contradiction. One day, I spent an afternoon at a school in the slums of Mathare, holding hands with dirty children that were happy to simply swing arms with me. Most of these children were AIDS orphans. They grinned shyly at me, gently trying to push one another away for the honor of holding the white visitor's hand, smiling their innocent smiles and pulling at my wrists, palms, and fingers with their grimy, un-washed little hands. As the group I was with left, we waved goodbye to the children as they scurried out after us, still grinning. We exited past mounds of filth, composed of trash and human and animal feces, which ragged goats and chickens picked through.

I finished this same day seated in a beautiful living room, the taint of the slum having been washed from me, seated in a plush chair, listening to music and light conversation while being served red wine and appetizers by a Kenyan servant. This was a dinner party at the house of a friend, another intern whose father is the ambassador of an Asian country to all of East Africa. I have been told that these extreme polarities are simply what life is like in a developing country. Yet, it was difficult to make sense of it, and disorienting to live in both extremes. I often simply felt bewildered.

\section{Disparate Lives Meet in Nairobi}

I found that as displaced as I was in Nairobi, I was often surprised at the simplicity to be enjoyed in familiar tasks taking place in an entirely different context. I realized that, to maintain my sanity, I would have to choose to focus on experiences that I could share with others and make sense of. For me, this may be the most appealing aspect of traveling: to fall into the everyday occurrences of an alien land, and for at least a moment to feel a part of them, understanding them--if one is daring enough-and,thus, enjoying them all the more.
Jennifer Venema is a senior in the BSCRP program, Cal Poly San Luis Obispo. In 2007 she was the recipient of the Ludvigsen and the Berrier Memorial scholarships, and the Hay Award for Environmental and Sustainable Design.

She is interested in international development and she has been a constant contributor to FOCUS.

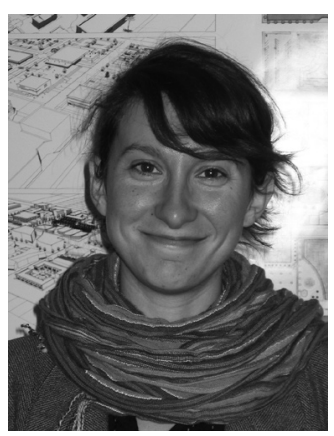

Note: Portions of this article appeared earlier in InterPlan, and are reproduced courtesy of the International Division of the American Planning Association. 


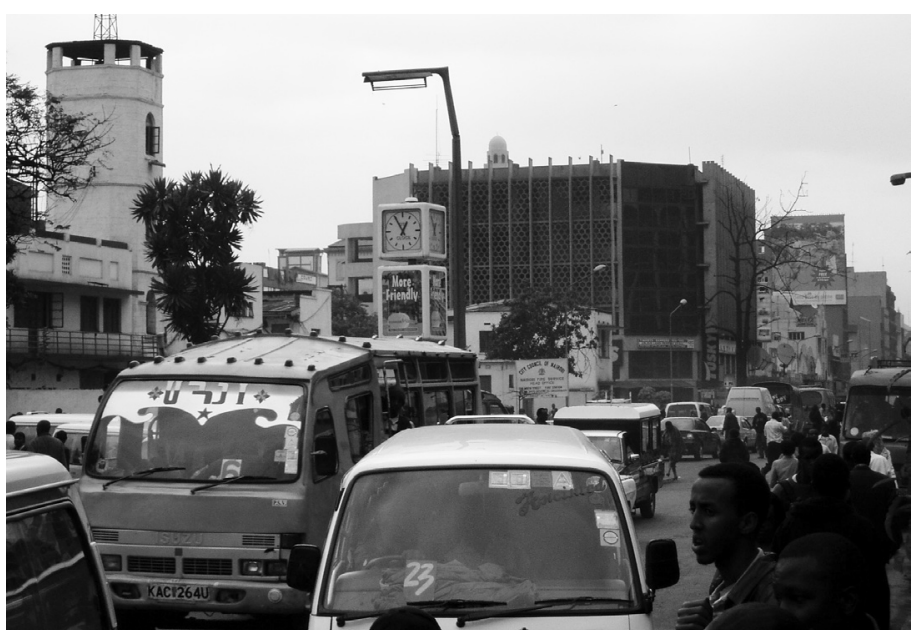

Figure 1 Traffic in central Nairobi.
German planner, three Americans, one Indian-American, and their friends - which were often of some European nationality.

All together, this random assortment of people often made the weekly shared meal all the more enjoyable. I often found myself savoring flavors, listening to familiar American political conversation (which it seems impossible to escape, the world over), and partaking of this experience with diverse people from four different continents. Who would ever guess how many disparate lives can be brought together over Punjabi curry in an old bachelor's home? And how many other similar occurrences take place everyday around the world, whenever people find something to share? In traveling it becomes easy, and at times, essential, to focus on commonalities between people. It often served for me as the starting point of fruitful friendships and rich experiences.

The primary commonality that defined my identity in Nairobi was that I was an intern at the United Nations Human Settlements Programme. As soon as I arrived, I found that I was sharing a house with other interns in various United Nations divisions. I met plenty of other interns there as well.

Figure 2

Kenya's Parliament in central Nairobi.

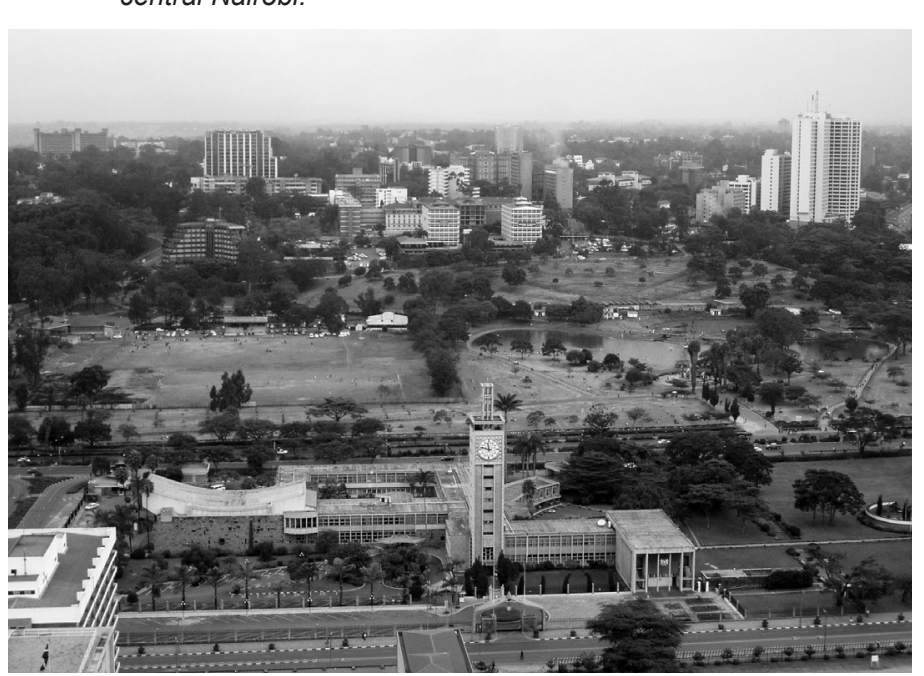
Furthermore, I met other interns who were also studying planning. Suddenly, despite the fact that I was in Africa, I found myself surrounded with people immersed in planning even more than I was, people with whom I shared common professional interests, some of them pursuing master's degrees and conducting thesis research.

My contact with these other young planners heightened my excitement about the field of planning and proved to me its diversity and usefulness. One acquaintance from Chile was practically living in a slum, initiating small, grass-roots projects, such as protecting a plot to maintain recreation space for children in the crowded slum, or trying to terrace land near the river to control erosion. Another friend had just come to Nairobi after doing field research in her native India, analyzing the politics of slum life. A German housemate was interviewing elite expatriate perceptions of public space in Nairobi, finding that, within it, elites did not perceive any such thing as public space, testifying to the
One example was the weekly barbeques of my landlord, which he invited his tenants to. There were, at one time, up to eight of us, living in an old four-bedroom house. Whenever with the arguments of a group of aging friends, arguments that had been playing themselves out nearly every Saturday afternoon for over two decades. My landlord was Indian by ethnicity, but a Kenyan citizen with friends that were also of a surprising assortment. There were Pakistanis, British expatriates, a Chinese importer, an Indian businessmen and lawyers in their casual Saturday dress, a KenyanBritish magazine editor, a diabetes nurse from Minnesota, and then, of course, the odd interns. During my stay, the interns consisted of a sarcastic Londoner, a tall and athletic Dutch student of energy policy, a black Dutch journalist, a 
privatized nature of the city. Yet another university student was interviewing recent immigrants to the slum of Mathare to understand what drew and kept them there despite hardships. In the process of these interviews, she ended up raising money from her native Holland to fund a women's group among some interviewees; this group eventually used the money to start a daycare center as an alternative for women to achieve a small measure of financial independence.

These diverse experiences illustrate what one with a background in planning can do once their imagination or interests are triggered. It was easy to be unduly intimidated by the experiences of many of the interns, but I tried to use my time with them as an opportunity to preview different aspects of the field and obtain ideas from those further along in their education and careers. I was able to use their insights to clarify my perceptions of the field of planning, and they were more than willing to let me pick their brains to understand the strengths and weaknesses of their graduate programs. I consider the relationships I built with other interns to be one of the most valuable aspects of my internship.

\section{The Internship Experience}

Asking fellow UN-HABITAT interns about their experiences and impression of the UN-HABITAT as an organization yielded varied answers, yet a significant number offered a common insight. They noted that while UN-HABITAT is a huge and sometimes inefficient organization, unable to implement its own proposals, in totality, it is the best the world has for the work it does. It is in a unique position, oriented with a global perspective to monitor and evaluate global trends to produce insight that can guide and instruct policy making in the realm of urban issues. It is singularly poised to initiate dialogue on issues of human settlements and cities that are of global concern.

Though critics may charge it with futility in offering knowledge and policy nobody actually implements, it is important to note that HABITAT's role is not implementation per se. HABITAT's mission is to "promote socially and environmentally sustainable human settlements development and the achievement of adequate shelter for all." HABITAT is working towards this by monitoring trends, facilitating dialogue, financing projects, and creating partnerships. It emphasizes the importance of partnerships and of empowering civil society and governments to play a positive role in issues pertaining to human settlements. It works to create resources that others can rely on and utilize. In a sense, it creates knowledge that is a collective good and will benefit many, of whom very few, if any, are either motivated or equipped to produce independently. And while this alone is not sufficient to solve all the problems facing cities today, it is a critical start.

HABITAT's work is not to supplant local actors; rather, it works to empower them. The Global Urban Observatory (GUO) of UN-HABITAT, where I interned, conducts much of the research and data generation of UNHABITAT, information which is then used to educate and equip local actors

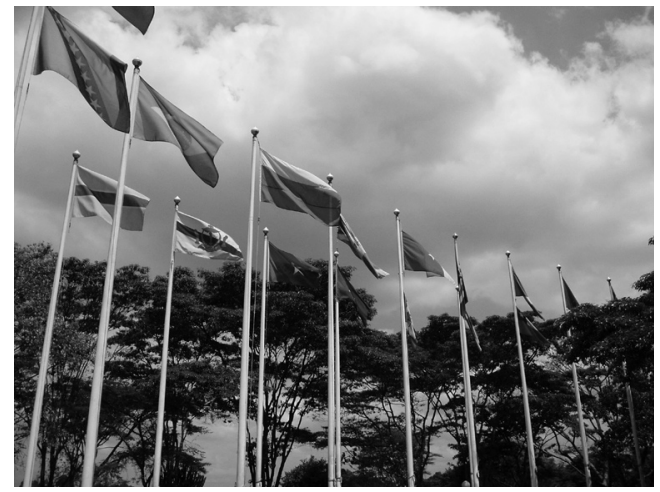

Figure 3

The flags lining the entry to the UN compound in Nairobi.

Figure 4

Typical Indian-style door carving in Zanzibar.

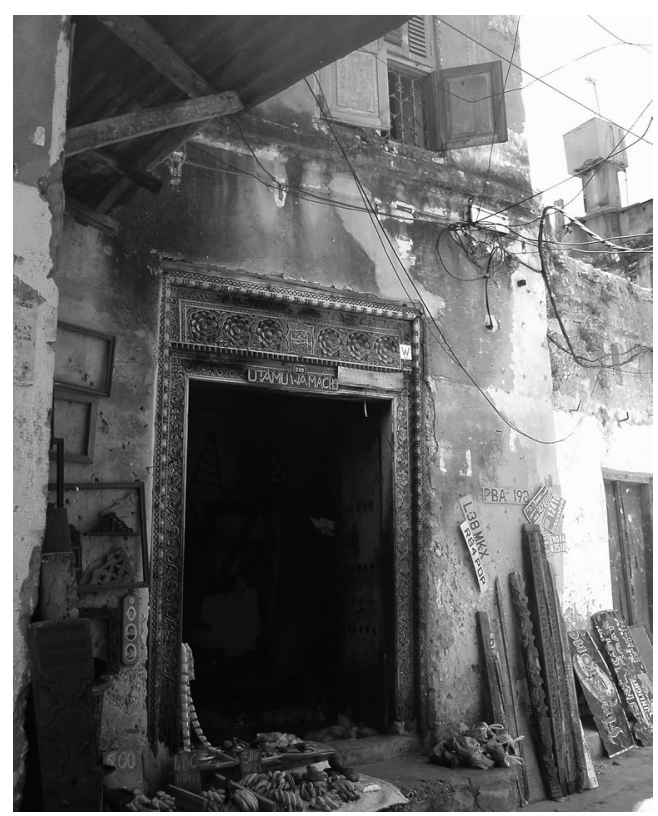




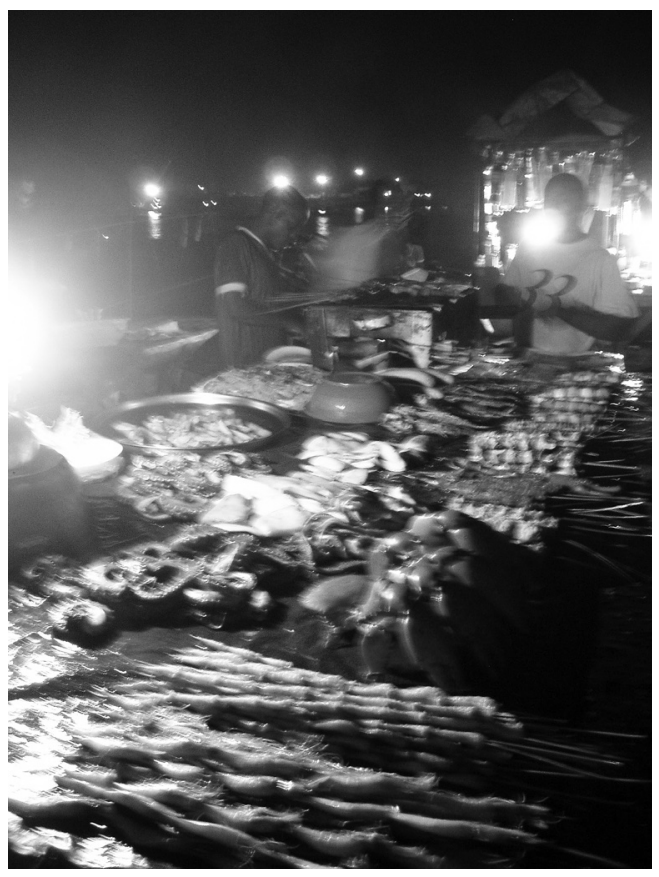

Figure 5

The fish market in Stone Town, Zanzibar.

Figure 6

The white beaches of Zanzibar.

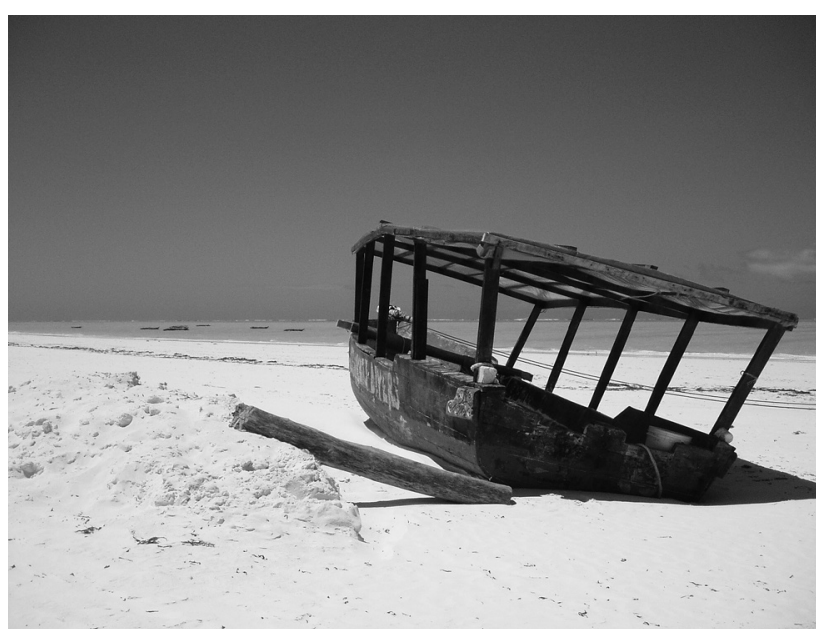

in city development. My internship involved one aspect of GUO's knowledge generation to instruct policymaking: the State of the World's Cities Report $2008 / 2009$. This is a flagship UN document that is produced once every two years, and is created to educate the layperson (decision makers, the media, non-governmental organizations, etc.) in order to lead to better city policy. This year's report is looking at the importance of integration of local, national, and regional policy in order to achieve a level of development that is sustainable in all aspects. It will synthesize a wealth of information to illustrate that coordinated development is critical in reducing inequality within cities. Rather than solely focus on economic growth, the city's importance and proper role as part of a national system needs to be taken into account in order to truly improve the lives of citizens. For more information is available in the State of World Cities Report 2008/9 published by UN-HABITAT, due to be released early 2008 .

My work on the report consisted entirely of research. I compiled a summary of city growth and decline trends for 135 cities in Latin America and the Caribbean, explaining factors according to a typology developed by my team. I also researched inequality measures for intra-city inequalities that depict disparities of wealth and income. My supervisor is now using my work in combination with that of other team members--which focused on the same topics but in different parts of the world--to create an in-depth global comparison and analysis of urban trends. This will form a portion of the body of the report. I also researched the provision of infrastructure in cities in the developing world to illustrate the importance of good policy in city government. Another supervisor used this work to depict that good policy can overcome the challenges of city growth, research that will also be used within the report.

\section{Justification of the Experience}

My experience was tremendously valuable from multiple perspectives. Primarily, I learned more about planning issues around the world and the professions of people involved in them. Secondly, I contributed to an important report that informs city policy. Thirdly, I learned about the complexities of a work environment and discovered the effort it requires to conduct deliberate and critical analysis in all work. Put shortly, my experience was indeed worth the miserable plane flight and tremendous amounts of money spent. I say this without even delving into my experiences of Nairobi as a city and the wonders of Kenya (including the Great Wildebeest Migration, one of the wonders of the natural world); describing these would require another story all together.

In conclusion, I encourage any student interested in traveling to pursue it--the beauty of studying planning is that we are studying the relationship between people and places, and that is a study which can be conducted virtually anywhere that people are to be found. Not only is planning relevant around the world, but one's insights into planning will only be improved by the number of places one is able to experience and understand. I think, as I am sure many other students and professors in our program do, traveling should be an important component of any planner's education. The experience 
of new places enriches one's understanding of the field. To get overseas, students can study abroad or try to work abroad. For those interested in working abroad, I recommend to be creative in their search and to look at websites of international organizations or firms. Do not be deterred if an internship is not paid; the experience justifies the burden of the costs. Cal Poly may be able to provide funds, and the International Division of the American Planning Association offers travel grants to students who are trying to study or work abroad. Also, be sure to utilize the resources you have, since professors have a wealth of information available to you. Now is the time for students to travel because it will only get more difficult the more entrenched into a career we become. For those graduating and wanting to get overseas, they should investigate the Fulbright Program or Peace Corps. There are venues out there help; it just takes a little determination to make it happen.

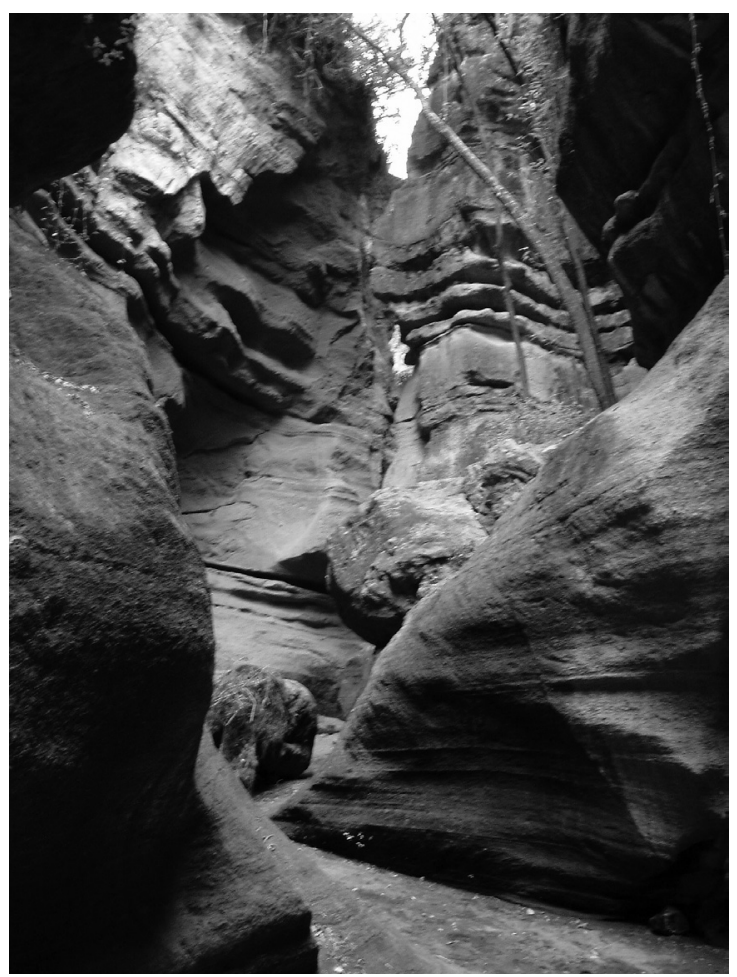

Figure 9

An incredible rock formation at Hell's Gate National Park in Kenya.

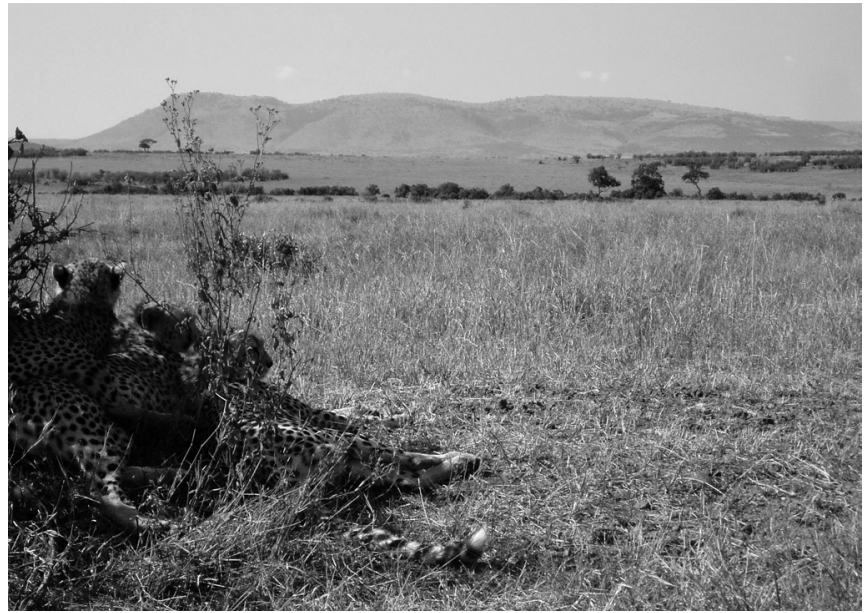

Figures 7 and 8

The cheetahs and the The UN interns on a safari on a safari in the Masai Hara

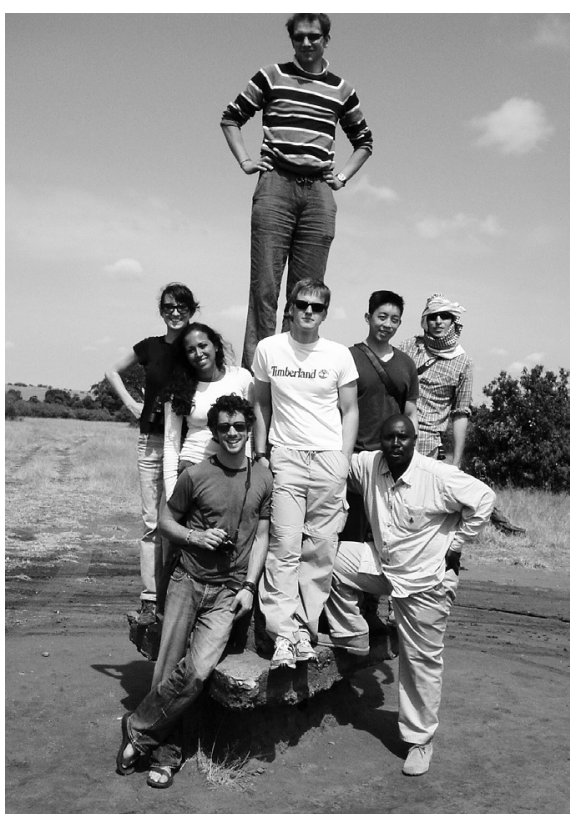

